\title{
Gambaran Zat Pewarna Merah pada Saus Cabai yang Terdapat pada Jajanan yang Dijual di Sekolah Dasar Negeri Kecamatan Padang Utara
}

\author{
Ilham Rizka Putra ${ }^{1}$, Asterina ${ }^{2}$, Laila Isrona ${ }^{3}$
}

\begin{abstract}
Abstrak
Saat ini, semakin banyak produsen makanan menggunakan zat pewarna yang sudah dilarang penggunaannya. Tujuan penelitian ini adalah untuk mengetahui gambaran zat pewarna pada saus cabai yang terdapat pada jajanan yang dijual di Sekolah Dasar Negeri Kecamatan Padang Utara pada bulan November 2013 - Februari 2014. Penelitian dilaksanakan di Balai Laboratorium kesehatan Padang. Metode yang digunakan adalah deskriptif dengan jumlah sampel sebanyak 25 sampel yang diambil dari pedagang makanan jajanan saus cabai yang terdapat di SD Negeri pada kecamatan Padang Utara. Pemeriksaan dilakukan secara kualitatif dengan menggunakan pereaksi kimia $\mathrm{NaOH} 10 \%, \mathrm{NH} 4 \mathrm{OH} 10 \%, \mathrm{HCl}$ pekat dan $\mathrm{H} 2 \mathrm{SO} 4$ pekat serta dilanjutkan dengan metoda kromatografi kertas untuk mendapatkan jenis zat pewarna yang terdapat didalam jajanan saus cabai. Hasil penelitian menunjukkan bahwa sebanyak 10 sampel (40\%) mengandung Rhodamin B dan 15 sampel (60\%) yang diizinkan penggunaannya. yaitu Erytrosin. Rata-Rata kadar Erytrosin dalam saus cabai adalah 639,5\% dari 300 mg/kg sampel yang diizinkan.
\end{abstract}

Kata kunci: saus cabai, zat pewarna berbahaya, kadar zat pewarna

\begin{abstract}
Nowadays more and more food manufacturers use dyes that have been banned uses. Applied this study is to describe the dye contained in the chili sauce snacks sold in Elementary School District of the northern desert in November 2013-February 2014. This research was conducted in Health Laboratoratorium Padang. The method used a descriptive with a sample size of 25 samples taken from street food vendors chili sauce found in the districts of $S D$ Negeri Kecamatan Padang Utara. Examination conducted qualitatively by using chemical reagents $\mathrm{NaOH} \mathrm{10 \% ,10 \%}$ $\mathrm{NH} 4 \mathrm{OH}$, and concentrated $\mathrm{HCl}$ and concentrated $\mathrm{H} 2 \mathrm{SO} 4$ followed by paper chromatography method to get the type of dye contained in chili sauce snacks. The results showed that 10 samples (40\%) containing Rhodamine $B$ and 15 samples (60\%) which allowed determination of use, Erytrosin. Concentration of Erytrosin, the average levels in the chili sauce as much as $639,5 \%$ of the $300 \mathrm{mg} / \mathrm{kg}$ samples were allowed.
\end{abstract}

Keywords: chili sauce, harmful dyes, dye concentration

Affiliasi penulis : 1. Fakultas Kedokteran Universitas Andalas Padang, 2. Bagian Kimia FK UNAND, 3. Bagian Farmakologi FK UNAND

Korespondensi : Ilham Rizka Putra, email: abil_gg@yahoo.co.id, Telp: +6281947673020

\section{PENDAHULUAN}

Makanan adalah salah satu kebutuhan manusia dalam kehidupan seharinya. Sebagai kebutuhan dasar, makanan tersebut harus mengandung zat gizi untuk dapat memenuhi fungsinya dan aman dikonsumsi, karena makanan yang tidak aman dapat menimbulkan gangguan kesehatan bahkan keracunan. ${ }^{1}$

Aneka produk makanan dan minuman yang berwarna-warni tampil semakin menarik. Warna-warni pewarna membuat aneka produk makanan mampu mengundang selera, walaupun demikian, konsumen harus berhati-hati. Badan Pengawas Obat dan Makanan (BPOM) sering menemukan produk makanan yang menggunakan pewarna tekstil. Pada era modern 
ini, bahan pewarna tampaknya sudah tidak bisa dipisahkan dari berbagai jenis makanan dan minuman olahan. Produsen pun berlomba-lomba untuk menarik perhatian para konsumen dengan menambahkan pewarna pada makanan dan minuman. ${ }^{2}$

Kasus penyalahgunaan bahan tambahan pangan yang biasa terjadi adalah penggunaan bahan tambahan yang dilarang untuk bahan pangan dan penggunaan bahan makanan melebihi batas yang ditentukan. Penyebab lain, produsen berusaha memenuhi kebutuhan dengan mendapat keuntungan besar, tetapi harga murah melalui penggunaan zat pewarna makanan yang digunakan untuk mempertahankan kondisi makanan agar menarik. ${ }^{3}$

Pemerintah Indonesia melalui Peraturan Menteri Kesehatan (Permenkes) No.239/Menkes/Per/ V/85 menetapkan 30 zat pewarna berbahaya. Rhodamine B termasuk salah satu zat pewarna yang dinyatakan sebagai zat pewarna berbahaya dan dilarang digunakan pada produk pangan. ${ }^{4}$ Namun demikian, penyalahgunaan Rhodamine B sebagai zat pewarna pada makanan masih sering terjadi di lapangan dan diberitakan di beberapa media massa, sebagai contoh; rhodamine $B$ ditemukan pada makanan dan minuman seperti kerupuk, sambal botol dan sirup di Makassar pada saat BPOM Makassar melakukan pemeriksaan sejumlah sampel makanan dan minuman ringan. ${ }^{5}$

Zat pewarna makanan merupakan suatu senyawa berwarna yang memiliki afinitas kimia terhadap benda yang diwarnainya. Warna suatu produk makanan ataupun minuman merupakan salah satu ciri yang sangat penting. Warna merupakan kriteria dasar untuk menentukan kualitas makanan, antara lain warna juga dapat memberi petunjuk mengenai perubahan kimia dalam makanan, seperti pencoklatan. $^{1}$

Beberapa negara maju, seperti Eropa dan Jepang telah melarang penggunaan pewarna sintetis seperti pewarna tartrazine dimana lebih merekomendasikan pewarna alami, seperti beta karoten, walaupun demikian pewarna sintetis masih sangat diminati oleh para produsen makanan alasannya harga pewarna sintetis jauh lebih murah dibandingkan dengan pewarna alami, selain itu pewarna sintetis memiliki tingkat stabilitas yang lebih baik, sehingga warnanya tetap cerah meskipun sudah mengalami proses pengolahan dan pemanasan. ${ }^{2}$

Pemerintah Indonesia melalui Menteri Kesehatan RI telah mengeluarkan Surat Keputusan tentang jenis pewarna alami dan sintetik yang diizinkan, serta yang dilarang digunakan dalam makanan pada tanggal 1 Juni 1979 No.235/Menkes/Per/VI/79, kemudian disusul dengan Surat Keputusan Menteri Kesehatan RI tanggal 1 Mei 1985 No. 239/Menkes/Per/ $\mathrm{V} / 85$, yang berisikan jenis pewarna yang dilarang. Terakhir telah dikeluarkan pula Surat Keputusan Menteri Kesehatan Nomor 722/Menkes/Per/IX/88, yang mengatur batas maksimum penggunaan dan pewarna yang diizinkan di Indonesia. ${ }^{6}$

Bahan pewarna yang sering digunakan dalam makanan olahan terdiri dari pewarna sintetis (buatan) dan pewarna natural (alami). Pewarna sintetis terbuat dari bahan kimia, seperti Tartrazin untuk warna kuning atau Alleura red untuk warna merah, kadangkala pengusaha yang nakal menggunakan pewarna bukan makanan untuk memberikan warna pada makanan. Agar mendapat keuntungan, produsen sering menggunakan pewarna tekstil untuk makanan, ada yang menggunakan Rhodamin B pewarna tekstil untuk mewarnai terasi, kerupuk dan minuman sirup sedangkan penggunaan pewarna jenis itu dilarang keras, karena bisa menimbulkan kanker dan penyakit lainnya. Pewarna sintetis yang boleh digunakan untuk makananpun harus dibatasi penggunaannya, karena pada dasarnya, setiap senyawa sintetis yang masuk ke dalam tubuh akan menimbulkan efek. ${ }^{7}$

Berbeda dengan pewarna alami yang malah mudah mengalami pemudaran pada saat diolah dan disimpan sebenarnya, pewarna alami tidak bebas dari masalah. Menurut Lembaga Pengkajian Pangan Obatobatan dan Kosmetika Majelis Ulama Indonesia (LPPOM MUI) dari segi kehalalan, pewarna alami justru memiliki titik kritis yang lebih tinggi, dikarenakan pewarna natural tidak stabil selama penyimpanan, maka untuk mempertahankan warna agar tetap cerah, sering digunakan bahan pelapis untuk melindunginya dari pengaruh suhu, cahaya dan kondisi lingkungan. ${ }^{1}$

Penambahan zat pewarna pada makanan dilakukan untuk memberi kesan menarik bagi konsumen, menyeragamkan warna makanan, men- 
stabilkan warna dan menutupi perubahan warna selama penyimpanan. Penambahan zat pewarna rhodamine B pada makanan terbukti mengganggu kesehatan, misalnya mempunyai efek racun, berisiko merusak organ tubuh dan berpotensi memicu kanker, oleh karena itu rhodamine B dinyatakan sebagai pewarna berbahaya dan dilarang penggunannya. ${ }^{8}$

Pemerintah $\mathrm{Rl}$ telah mengatur penggunaan zat pewarna dalam makanan, namun demikian masih banyak produsen makanan, terutama pengusaha kecil, yang menggunakan zat-zat pewarna yang dilarang dan berbahaya bagi kesehatan, misalnya pewarna untuk tekstil atau cat yang pada umumnya mempunyai warna yang lebih cerah, lebih stabil dalam penyimpanan, harganya lebih murah dan produsen pangan belum menyadari bahaya dari pewarnapewarna tersebut.Bahan pewarna sintetik yang sering dipakai untuk produk makanan contohnya adalah pemakaian bahan pewarna tekstil Methanil Yellow dalam pembuatan tahu, atau pembuatan manisan mangga, bahan pewarna dilarang Rhodamin B dalam jajanan es campur serta bahan pewarna Tartrazine untuk produk sirup, limun. ${ }^{9}$

Utami ditahun 2005 telah melakukan penelitian tentang zat pewarna yang terdapat pada makanan jajanan yang terdapat di pasaran di Jakarta, ternyata dari 31 sampel yang diuji didapatkan 10 sampel yang mengandung zat pewarna sintetik yang dilarang untuk makanan yaitu; satu sampel Orange G, satu sampel Methanil yellow, satu sampel Chocolate Makanan yang beredar di masyarakat memiliki warna yang bermacam-macam dan kebanyakan menggunakan zat warna sintetik. Adanya peraturan yang telah ditetapkan, diharapkan keselamatan konsumen dapat terjamin tetapi kenyataannya tidaklah demikian. ${ }^{9}$

Penjual makanan di pinggiran jalan sudah biasa menggunakan bahan tambahan makanan termasuk zat warna yang tidak diijinkan, ini disebabkan karena bahan itu mudah diperoleh dalam kemasan kecil di toko dan pasar dengan harga murah. Penjual makanan menggunakan zat warna tekstil ini karena kesengajaan atau ketidaktahuan, sedangkan produsen makanan bertujuan menghasilkan warna yang lebih menarik, yang dikiranya aman. ${ }^{9}$
Makanan jajanan yang dijual oleh pedagang kaki lima atau dalam bahasa Inggris disebut street food menurut "Food and Agriculture Organization" didefinisikan sebagai makanan dan minuman yang dipersiapkan dan dijual oleh pedagang kaki lima di jalanan dan di tempat keramaian umum yang langsung dimakan dan dikonsumsi tanpa persiapan atau pengolahan lebih lanjut. ${ }^{10}$

Saus merupakan bahan pelengkap yang digunakan sebagai tambahan untuk menambah kelezatan makanan dapat berupa cairan kental (pasta) yang terbuat dari bubur buah berwarna menarik (biasanya merah), mempunyai aroma dan rasa yang merangsang (dengan atau tanpa rasa pedas), mempunyai daya simpan panjang karena mengandung asam, gula, garam dan seringkali pengawet. ${ }^{11}$

Kecamatan Padang Utara merupakan salah satu kecamatan yang terdapat di Kota Padang dimana terdapat 13 SD Negeri dan merupakan kecamatan yang terbanyak jumlah SD Negerinya. ${ }^{12}$

Berdasarkan latar belakang di atas maka peniliti tertarik untuk melakukan penelitian tentang pemeriksaan zat pewarna pada saus cabe yang dijual di Sekolah Dasar Negeri yang terdapat pada kecamatan Padang Utara.

\section{METODE}

Penelitian ini adalah penelitian deskriptif. Pengambilan sampel penelitian dilakukan di semua SD Negeri yang terdapat pada Kecamatan Padang Utara. Pemeriksaan jenis dan kadar dari zat pewarna sampel dilakukan di Laboratorium Kesehatan, Gunung Pangilun Padang pada bulan November 2013Februari 2014.

Populasi pada penelitian ini adalah seluruh pedagang yang menggunakan saus cabe yang berada di SD Negeri yang terdapat di Kecamatan Padang Utara yang berjumlah 13 SD dan 25 pedagang yang menggunakan saus cabai.

Sampel adalah bagian dari populasi dimana teknik pengambilan sampel dilakukan adalah seluruh penjual saus cabe secara total sampling pada SDN yang terdapat di Kecamatan Padang Utara, kemudian masing-masingnya diberi kode tertentu yaitu berjumlah 25 sampel. 
HASIL

\section{Lokasi Survei}

Pedagang yang menjual saus yang berada di daerah Lolong Belanti, Ulak Karang, Asrama Polisi, Belakang Taman Makam Pahlawan, Jalan Pramuka pada umumnya saus yang dijual ada yang dibuat sendiri dan ada pula yang dibeli di pasar yang terdekat.

Tabel 1. SD Negeri, Jumlah Pedagang dan Asal Saus yang Terdapat di Kecamatan Padang Utara

\begin{tabular}{ccccc}
\hline & \multirow{2}{*}{ No. } & Nama & Jumlah & \multicolumn{2}{c}{ Asal saus } \\
\cline { 4 - 5 } & SD N & Pedagang & $\begin{array}{c}\text { Buatan } \\
\text { sendiri }\end{array}$ & Dibeli \\
\hline 1. & SD N 11 & 2 & 2 & - \\
2. & SD N 13 & 3 & 2 & 1 \\
3. & SD N 14 & 2 & 1 & 1 \\
4. & SD N 15 & 2 & 1 & 1 \\
5. & SD N 23 & 2 & 2 & - \\
6. & SD N 01 & 2 & 1 & 1 \\
7. & SD N 02 & 2 & 2 & - \\
8. & SD N 07 & 1 & 1 & - \\
9. & SD N 08 & 1 & 1 & - \\
10. & SD N 12 & 2 & 1 & 1 \\
11. & SD N 27 & 2 & 2 & - \\
12 & SDN 22 & 2 & 1 & 1 \\
13. & SD N 29 & 2 & - & 2 \\
\hline & Jumlah & 25 & 17 & 8
\end{tabular}

Pada tabel 1 didapatkan dari 25 pedagang saus cabai yang didapat dari 13 SD Negeri di Kecamatan Padang Utara, 17 (72\%) pedagang membuat saus sendiri dan 8 (28\%) pedagang membeli saus di pasar terdekat .

\section{Hasil Pemeriksaan}

Dari 25 sampel saus cabai yang sudah diperiksa kandungan zat pewarnanya ternyata 10 sampel positif (40\%) mengandung zat pewarna yang sudah dilarang oleh Depkes RI (zat berbahaya).
Tabel 2. Frekuensi Saus Cabai Mengandung Zat Pewarna Merah yang Dijual di SD Kecamatan Padang Utara

\begin{tabular}{|c|c|c|c|}
\hline \multirow[t]{2}{*}{ No.Sampel } & \multicolumn{2}{|c|}{$\begin{array}{c}\text { Saus cabai yang } \\
\text { mengandung zat } \\
\text { pewarna yang } \\
\text { diizinkan Depkes RI }\end{array}$} & \multirow{2}{*}{$\begin{array}{c}\text { Saus cabai } \\
\text { yang } \\
\text { mengandung } \\
\text { zat pewarna } \\
\text { yang dilarang } \\
\text { Depkes RI }\end{array}$} \\
\hline & $\begin{array}{c}\text { Ponceau } \\
\text { sX }\end{array}$ & Erytrosin & \\
\hline S-1 & - & + & \\
\hline S-2 & - & + & \\
\hline S-3 & - & & + \\
\hline S-4 & - & & + \\
\hline S-5 & - & + & \\
\hline S-6 & - & + & \\
\hline S-7 & - & & + \\
\hline S-8 & - & + & \\
\hline S-9 & - & & + \\
\hline S-10 & - & + & \\
\hline$S-11$ & - & + & \\
\hline S-12 & - & & + \\
\hline$S-13$ & - & & + \\
\hline S-14 & - & + & \\
\hline S-15 & - & + & \\
\hline S-16 & - & + & \\
\hline S-17 & - & + & \\
\hline S-18 & - & & + \\
\hline S-19 & - & & + \\
\hline S-20 & - & + & \\
\hline$S-21$ & - & + & \\
\hline S-22 & - & + & \\
\hline S-23 & - & & + \\
\hline S-24 & - & + & \\
\hline S-25 & - & & + \\
\hline Total & - & 15 & 10 \\
\hline
\end{tabular}

Pada tabel 2 dapat dilihat dari 25 saus cabai yang diperiksa ternyata ditemukan sampel saus cabai yang dilarang penggunaannya (berbahaya) yaitu Rhodamin B (40\%) dan zat pewarna yang diizinkan penggunaannya/Erytrosin (60\%) sedangkan Ponceau SX tidak ditemukan. 
Tabel 3. Jenis Zat Pewarna Berdasarkan Asal Saus Cabai yang Terdapat di SDN Kecamatan Padang Utara

\begin{tabular}{|c|c|c|c|c|c|c|}
\hline \multirow{4}{*}{$\begin{array}{l}\text { Nama } \\
\text { SD N }\end{array}$} & \multicolumn{6}{|c|}{ Asal saus cabai } \\
\hline & \multicolumn{3}{|c|}{ Buatan sendiri } & \multicolumn{3}{|c|}{ Dibeli } \\
\hline & \multirow{2}{*}{$\begin{array}{c}\text { Berbahaya } \\
\text { Rhodamin } \\
\text { B }\end{array}$} & \multicolumn{2}{|c|}{ Tidak berbahaya } & \multirow{2}{*}{$\begin{array}{c}\text { Berbahaya } \\
\text { Rhodamin } \\
\text { B }\end{array}$} & \multicolumn{2}{|c|}{ Tidak berbahaya } \\
\hline & & Erytrosin & $\begin{array}{c}\text { Ponceau } \\
\text { sx }\end{array}$ & & Erytrosin & $\begin{array}{c}\text { Ponceau } \\
\text { sx }\end{array}$ \\
\hline SD 11 & - & 2 & - & - & - & - \\
\hline SD 13 & 2 & - & - & 1 & - & - \\
\hline SD 14 & 1 & - & - & 1 & - & - \\
\hline SD 15 & 1 & - & - & - & 1 & - \\
\hline SD 23 & - & 2 & - & - & - & - \\
\hline SD 01 & 1 & - & - & 1 & - & - \\
\hline SD 02 & - & 2 & - & - & - & - \\
\hline SD 07 & - & 1 & - & - & - & - \\
\hline SD 08 & - & 1 & - & - & - & - \\
\hline SD 12 & 1 & - & - & 1 & - & - \\
\hline SD 27 & - & 2 & - & - & - & - \\
\hline SD22 & 1 & - & - & 1 & - & - \\
\hline SD 29 & - & - & - & 2 & - & - \\
\hline Jumlah & 7 & 10 & - & 3 & 5 & - \\
\hline
\end{tabular}

Pada tabel 3, dapat dilihat dari 25 pedagang saus cabai, ternyata 17 pedagang membuat saus sendiri dimana 7 sampelnya mengandung zat pewarna yang berbahaya (41\%) dan dari 8 sampel yang dibeli didapat 3 sampel yang berbahaya $(37,5 \%)$.

Tabel 4. Penentuan Kadar Zat Pewarna pada Saus Cabai yang Diizinkan Penggunaannya

\begin{tabular}{ccc}
\hline No.Sampel & $\begin{array}{c}\text { Kadar zat pewarna } \\
\text { sampel } \\
\text { mg/kg sampel }\end{array}$ & $\begin{array}{c}\text { Kadar Eritrosin yang } \\
\text { melebihi ketentuan } \\
\text { Depkes RI( < 300 } \\
\text { mg/kg sampel) }\end{array}$ \\
\hline S-1 & 3316,72 & 3016,72 \\
S-2 & 1724,94 & 1424,94 \\
S-5 & 2544,72 & 2244,72 \\
S-6 & 2629,82 & 2329,82 \\
S-8 & 1808,2 & 1508,2 \\
S-10 & 2200,24 & 1900,24 \\
S-11 & 2684,16 & 2384,16 \\
S-14 & 1550,24 & 1250,24 \\
S-15 & 2458,6 & 2158,6 \\
S-16 & 1326,74 & 1026,74 \\
S-17 & 2877,72 & 2577,72 \\
S-20 & 1469,26 & 1169,26 \\
S-21 & 2319,18 & 2019,18 \\
S-22 & 2209,68 & 1909,68 \\
S-24 & 2162,32 & 1862,32 \\
Rerata & & $28777,5: 15=1918,5$ \\
\hline & & \\
\hline
\end{tabular}

Keterangan :

Kadar konsentrasi yang lebih dari sampel $=1918,5 /$ $300 \times 100 \%=639,5 \%$

Pada tabel 4 didapatkan 15 sampel (60\%) mengandung zat pewarna yang diizinkan penggunaannya dan kadarnya melebihi standar yang ditentukan oleh DepKes RI.

\section{PEMBAHASAN}

\section{Cakupan Penjual Saus Cabai Yang Diteliti}

Pada tabel 1 dari 25 pedagang saus cabai yang didapat dari 13 SD Negeri di Kecamatan Padang Utara, asal saus cabenya lebih banyak buatan sendiri yaitu 17 pedagang (72\%) dan 8 dibeli di pasar terdekat (28\%). Sampel diambil berasal dari sekitar Lolong Belanti, Dibelakang Taman Makam Pahlawan Lolong, Dekat Asrama Polisi Lolong,Ulak Karang, Dekat Pasar Ulak Karang, Bung Hatta, jalan Pramuka dan Asratek Padang.

Badan Pengawas Obat dan makanan juga pernah melakukan penelitian terhadap saus cabe pada jajanan anak sekolah pada bulan November 2006,dimana dari 15 sampel ditemukan 10 saus cabe yang dibuat sendiri oleh pedagang. ${ }^{3}$

\section{Frekuensi Saus cabai yang mengandung zat pewarna merah yang dijual di SD Kecamatan Padang Utara}

Pada tabel 2 dapat dilihat dari 25 saus cabai yang diperiksa ternyata ditemukan sampel saus cabai yang dilarang penggunaannya (berbahaya) yaitu Rhodamin B sebanyak 10 sampel (40\%) dan zat pewarna yang diizinkan penggunaannya / Erytrosin 15 sampel (60\%) sedangkan Ponceau SX tidak ditemukan.

Penelitian sesuai dengan penelitian yang dilakukan oleh Utami pada tahun 2005 yang telah melakukan penelitian tentang zat pewarna yang terdapat pada makanan jajanan yang terdapat di pasaran di Jakarta, ternyata dari 31 sampel yang diuji didapatkan 10 sampel yang mengandung zat pewarna sintetik yang dilarang untuk makanan yaitu; satu sampel Orange G, satu sampel Methanil yellow, satu 
sampel Chocolate browm FB, dua sampel Rhodamin B, dua sampel Scarlet G.N dan 3 sampel merah K4. ${ }^{9}$

Menurut LPK2K, zat pewarna berbahaya ini sangat dilarang karena mengakibatkan kemunduran kerja otak,sehingga anak malas, sering pusing, dan menurunnya konsentrasi belajar. ${ }^{8}$

Penelitian ini sesuai dengan penelitian yang telah dilakukan dari 25 sampel saus cabe yang dijual di SD Negeri yang terdapat di Kecamatan Padang Utara yaitu didapat 10 sampel (40\%) yang mengandung zat pewarna yang berbahaya dan dilarang oleh Depkes RI yaitu Rhodamin B dan 15 sampel lainnya yang diizinkan penggunaannya yaitu Erytrosin.

\section{Jenis Zat Pewarna berdasarkan asal saus cabai yang terdapat di SDNKecamatan Padang Utara}

Pada tabel 3 terlihat dari 25 pedagang saus cabai, ternyata 17 pedagang membuat saus sendiri dimana 7 sampelnya mengandung zat pewarna yang berbahaya $(41 \%)$ dan dari 8 sampel yang dibeli didapat 3 sampel yang berbahaya (37,5\%).

Pasar tradisional merupakan tempat umum yang banyak menjual berbagai macam produk makanan termasuk saus yang dibeli oleh semua golongan masyarakat. Hasil penelitian Anominus di Pasar sentral dan Pasar Simpang Limun kota Medan didapatkan masih banyak saus cabai yang dipasarkan tidak mencantumkan jenis zat pewarna yang digunakan pada saus cabai tersebut dan dijual dalam bentuk kemasan plastik dengan harga yang sangat murah sehingga dikhawatirkan terjadinya penyimpangan dalam penggunaan zat pewarna sebagai bahan tambahan makanan pada saus cabai tersebut.

\section{Penentuan kadar zat pewarna pada Saus cabai yang diizinkan penggunaannya}

Pada tabel 4 dapat dilihat 15 sampel (60\%) zat pewarna yang diizinkan penggunaannya dan semua sampel melewati kadar yang ditentukan DepKes RI.

Hasil penelitian oleh Anonimus 2009 terhadap kadar zat pewarna makanan yang diizinkan penggunaannya ditemukan 7 dari 21 sampel yang diambil di Makasar melebihi aturan yang ditentukan DepKes RI. Timbulnya penyalahgunaan pemakaian zat pewarna berbahaya disebabkan oleh ketidaktahuan masyarakat mengenali zat pewarna untuk pangan, disamping itu harga zat pewarna industri jauh lebih murah dibandingkan dengan zat pewarna pangan. $^{8}$

Hasil penelitian ini dapat dinyatakan bahwa saus cabe yang digunakan sebagai pelengkap dari makanan jajanan yang dijual oleh pedagang belum sepenuhnya terbebas dari zat pewarna berbahaya baik dari jenis zat pewarna yang sudah dilarang penggunaannya maupun kadar yang melewati ketentuan dari DepKes RI $\quad(<300$ mg/kg berat sampel). ${ }^{6}$

\section{KESIMPULAN}

Berdasarkan penelitian yang telah dilakukan terhadap 25 sampel saus cabe yang dijual pada beberapa SD Negeri dan sekitarnya di Kecamatan Padang Utara,didapatkan:

1. Sebanyak 10 sampel saus cabe (40\%) yang mengandung zat pewarna yang berbahaya yaitu Rhodamin B.

2. Sebanyak 15 sampel saus yang diizinkan oleh Depkes RI yang telah ditentukan kadarnya ternyata semua sampel melewati kadar yang diperbolehkan Depkes RI (300 mg/kg berat sampel) dengan kadar konsentrasi sebanyak $639,5 \%$ dari $300 \mathrm{mg} / \mathrm{kg}$ berat sampel yang diizinkan.

\section{DAFTAR PUSTAKA}

1. Cahyadi W. Analisis \& aspek kesehatan bahan tambahan makanan. Edisi ke-2. Bandung: Bumi Aksara; 2009.

2. Surdijati, Anyar S, Lanni W. Identifikasi dan penetapan kadar zat warna merah dalam dawet secara KLT-densitometri. Yogyakarta: Kanisius; 2010.

3. Mukaromah. Identifikasi zat warna rhodamin B pada lipstik bewarna merah (skripsi). Semarang: Fakultas Farmasi Universitas Muhamadiyah; 2008.

4. Syah P. Manfaat dan bahaya bahan tambhan makanan. Jakarta: Balai Penerbit FK UI; 2005.

5. Anonimus. Gambaran Rhodamin B yang ditemukan pada makanan dan minuman di Makassar (skripsi). Makassar: Fakultas Kedokteran 
Universitas Hassanuddin; 2009.

6. Depkes RI. Batas maksimum penggunaan zat pewarna yang diizinkan di Indonesia. Permenkes RI No. 293/Menkes/Per/V/85; 2011.

7. Sarmalin O. Identifikasi pewarna sintetik pada produk pangan yang beredar di Jakarta dan Ciputat. Artikel Karya Tulis IImiah. Jakarta: Universitas Indonesia; 2010.

8. Azizahwati. Analisis zat warna sintetik terlarang untuk makanan (skripsi). Jakarta: Universitas Indonesia; 2007.

9. Utami D. Analisis zat warna merah, kuning dan jingga sintetik golongan azo pada beberapa makanan bewarna merah, kuning dan jingga. Jakarta: Departemen Farmasi FMIPA UI; 2005.

10. Winarno. Bahan tambahan untuk makanan dan kontaminan. Jakarta: Pustaka Sinar Harapan; 2002.

11. Saparianto, Cahyo, Diana HS. Bahan tambahan pangan. Dalam Dasar-Dasar Kimia Klinis Edisi ke4. Jakarta: Sagung Seto; 2011.

12. Dinas Pendidikan Kota Padang. Profil pendidikan kota Padang tahun 2010. Padang: Diknas; 2011. 